\title{
«Estando ausente Carlos, / ¿qué importa que las festivas voces le aplauden, si nada escucha?»: las loas a los años del rey Carlos II de sor Juana Inés de la Cruz \\ «Being absent Carlos, / what difference do the festive voices applauding him make if he hears nothing?»: Sor Juana's loas for King Carlos the Second's birthday
}

\section{Robin Ann Rice}

Universidad Popular Autónoma del Estado de Puebla Departamento de Artes y Humanidades

21 Sur 1103, Col. Santiago

72160 Puebla, MÉXICO

niborecir@hotmail.com

[Hipogrifo, (issn: 2328-1308), 1.1, 2013, pp. 87-104]

Recibido: 14-02-2013 / Aceptado: 05-03-2013

DOI: http://dx.doi.org/10.13035/H.2013.01.01.07

Resumen. A partir de 1650, Calderón de la Barca asignó un nuevo papel a la loa y la elevó artísticamente al nivel del auto. En América, sor Juana Inés de la Cruz siguió la batuta del español, y engrandeció la loa panegírica e incorporó los elementos de rigor: personajes alegóricos, fragmentos herméticos, reminiscencias emblemáticas y una ambientación sensorial. Estas loas son piezas que siguen ciertas 'plantillas' para glorificar al poder y exaltar la autoridad. Estas plantillas se componen de «paradigmas compositivos que estructuran en parte o en el diseño global su arquitectura argumental y estilística» como acierta Arellano sobre el auto sacramental pero, también es aplicable a las loas panegíricas sorjuaninas de la última mitad del siglo XVII. Propongo un análisis de las cinco loas que la monja compuso para el cumpleaños de Carlos II que consiste en identificar los paradigmas compositivos y compararlos entre sí para poder formular una estructura en tres actos basada en la identificación funcional de los paradigmas. 
Palabras clave. Sor Juana Inés de la Cruz, loa, Carlos II, estructura dramática.

Abstract. Starting in 1650, Calderón de la Barca assigned a new role to the 'loa', elevating it artistically to the level of the 'auto'. In America, Sor Juana Inés de la Cruz followed the Spaniard's example by aggrandizing the panegyric loa and including the essential elements: allegorical characters, hermetic fragments, emblematic reminiscences and a sensorial setting. These loas are pieces that adhere to certain templates to glorify power and exalt authority. These templates are constituted of compositional paradigms that structure the design, in part or as a whole, of the stylistic and argumentative architecture, as Arellano correctly asserts about the Auto Sacramental but also applicable to Sor Juana's last half of the $17^{\text {th }}$ century panegyric loas. I propose an analysis of the five loas that the nun composed for Carlos the Second's birthday that consists in identifying and comparing the compositional paradigms, to be able to formulate a three act structure based on the functional identification of the paradigms.

Keywords. Sor Juana Inés de la Cruz, Loa, Carlos II, Dramatic Structure.

A partir de 1650, Calderón de la Barca asignó un nuevo papel a la loa y la elevó artísticamente al nivel del auto. Antes de la década de los cincuenta, las loas sirvieron como prólogos, introitos o argumentos y por su «brevedad y su sencillez» eran «simples obritas líricas o didácticas recitadas por dos interlocutores, cuando

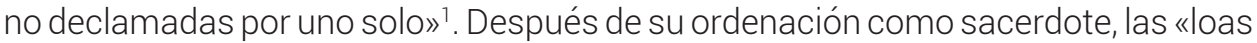
sacramentales calderonianas son ya breves piezas dramáticas, con mucho más variado y a veces hondo meollo doctrinal y con grande frecuencia de personajes alegóricos, llegando, en ocasiones a genuinos "Autos en miniatura"»². En la misma época, las loas palatinas, «preliminares para la comedia ante los Reyes [...] o Virreyes» también dieron la pauta para la nueva poética de la loa. En América, sor Juana Inés de la Cruz siguió la batuta del español, y engrandeció la loa panegírica e incorporó los elementos de rigor: personajes alegóricos, fragmentos herméticos, reminiscencias emblemáticas y una ambientación sensorial. Estas loas son piezas que siguen ciertas 'plantillas' para glorificar al poder y exaltar la autoridad. Estas plantillas se componen de «paradigmas compositivos que estructuran en parte o en el diseño global su arquitectura argumental y estilística» ${ }^{3}$ como acierta Arellano sobre el auto sacramental pero, también es aplicable a las loas panegíricas sorjuaninas de la última mitad del siglo XVII. Propongo un análisis de las cinco loas que la monja compuso para el cumpleaños de Carlos II que consiste en identificar los paradigmas compositivos y compararlos entre sí para poder formular una estructura en tres actos basada en la identificación funcional de los paradigmas.

Se aprecia el desarrollo de las loas que van desde los años del régimen del Arzobispo-Virrey, el padre Payo Enríquez (1673-1680) cuando el soberano cumplió 14 años o mayoría de edad como había decretado su padre Felipe IV, hasta las loas

1. Méndez Plancarte, 1995, pp. LII-LIV.

2. Méndez Plancarte, 1995, p. LIV.

3. Arellano, 2001, p. 19. 
que compuso durante la época de los marqueses de la Laguna que incluye la última conocida que celebra los 23 años de Carlos II en 1684. Varias de las loas contienen asuntos políticos y tantas alabanzas para los virreyes como para el Rey. Las loas para el natalicio del Rey y la comedia que seguía, formaban parte de una celebración en palacio para conmemorar tal acontecimiento. Sin embargo, es importante recordar que las celebraciones para el monarca español no comparaban en lujo y fasto con los agasajos para los virreyes vigentes. En el siglo XVII, había celebraciones locales para encomiar al rey en ciertas ocasiones, por ejemplo, el nacimiento de un heredero real, el casamiento del monarca, el embarazo de la reina, o, como en estas loas bajo examen, el cumpleaños del soberano. Como acierta Curcio-Nagy, estos eventos sirvieron para reforzar el papel del monarca en las vidas de sus soberanos lejanos, pero nunca, nunca, compitieron en fastuosidad con la entrada de los virreyes. Otro ejemplo de la soberanía de los virreyes sobre el rey, era que la jura del rey duraba un día y costaba la cuarta parte de las celebraciones de la entrada de los virreyes. Las festividades relacionadas con la llegada de los nuevos virreyes duraban meses ${ }^{4}$. Mientras el monarca era una figura distante y cuasi mítica, el virrey, representante del rey, poseía un poder real y tangible, influenciable y moldeable a metas y necesidades locales ${ }^{5}$. Pese a ser obras panegíricas, las loas son «una fusión prodigiosa de universos» ${ }^{6}$ e integran «las crisis, las preocupaciones y aspiraciones [...] de su tiempo» ${ }^{7}$, y por esto, mientras se estrecha la amistad entre sor Juana y los marqueses de la Laguna, las exaltaciones del poder se desvían más y más hacia los virreyes.

En su texto sobre las loas profanas de la monja, Octavio Rivera ${ }^{8}$ sugiere una correlación entre el dispositio de las obras y la repartición en escenas que Méndez Plancarte sobrepuso a las loas en su edición. Tanto la imposición de Méndez Plancarte de siete $u$ ocho escenas como la analogía entre las escenas y las funciones dramáticas que propone Rivera son imprecisas y no reflejan fielmente el contenido de la loa palaciega sorjuanina. Por lo tanto, si las loas palaciegas llegan a su apogeo en la última mitad del siglo XVII cuando son «[comedias] en miniatura» ${ }^{9}$, dividirlos en tres actos, sería más provechoso para el estudio. En su artículo «A propósito de las metáforas y los tópicos panegíricos en las loas palaciegas de la segunda mitad del siglo XVII» percibo que Judith Farré está apuntalando a lo mismo. Pues, en su análisis de algunas loas de Agustín de Salazar y Torres y Francisco Bances Candamo, sugiere ciertos paradigmas funcionales en todas las loas analizadas que se pueden traducir en actos ${ }^{10}$. El propósito de este escrito es de identificar y dividir las loas a los años del rey Carlos II de sor Juana Inés de la Cruz en tres actos según los paradigmas estructurales funcionales para poder comparar y contrastar la composición de estas obras entre sí e ilustrar cómo se insertan dentro del mismo

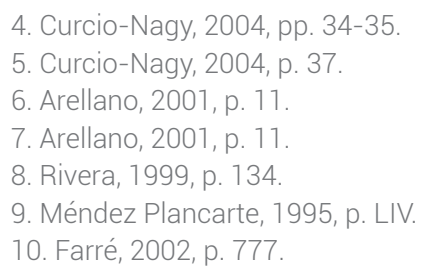


corpus estructural y estético de los más importantes compositores de loas de la última mitad del siglo XVII. En el análisis, se identifica la poética de la loa palatina sorjuanina y otros aspectos literarios transversales que son constantes en la obra panegírica de la monja. Los tres actos que propongo como estructura para el análisis y el estudio de las loas de la Décima Musa, identifico por las funciones que desarrollan dentro de la trama. El primer acto consiste en:

un debate de méritos en el que una serie de personajes alegóricos - generalmente se trata de una nómina de dos, tres o incluso cuatro, que a su vez pueden incorporar series paralelas y simétricas de coadyuvantes - trazan un debate de méritos en el que cada uno de ellos argumenta a partir de su definición alegórica para así conseguir la preeminencia en la celebración ${ }^{11}$.

La presentación del debate de méritos, corresponde a la instauración del conflicto o del nudo de la trama. El segundo acto corresponde al desenlace en el que: «se logra una solución consensuada al conflicto, generalmente a partir de la aparición de un juez mediador que demuestra la complementariedad simbólica de todas las propuestas festivas inicialmente enfrentadas» ${ }^{12}$. El tercer acto presenta literalmente la loa o aclamación a la persona elogiada en unísono y «[s]e consigue así caracterizar una realidad envolvente, sintomática de la grandeza del monarca al que va dirigido el homenaje de la representación» ${ }^{13}$.

Tenemos en la actualidad cinco loas que sor Juana escribió para los años del rey Carlos II. La loa más breve es la primera que consta de 390 versos mientras que la más extensa es la cuarta, escrita en 1683 y que se intitula: «Loa a los años del Rey [IV] que celebra José de la Cerda, primogénito del señor Virrey Conde de Paredes» y que se extiende hasta 620 versos. Es la más lograda de las loas y homenajea tanto al rey como al recién nacido José de la Cerda que contaba con cuatro meses.

\section{ACTO I}

El primer acto corresponde a las primeras tres escenas en la segmentación de las loas que propone Méndez Plancarte y que segunda funcionalmente Rivera. Predomina la luz en cuatro de las cinco loas, imagen común en los textos panegíricos áureos. Las diferentes formas, fuentes e intensidad de luz infiltren el escenario:

los orbes celestes paren

[...] Hoy, para el natal de Carlos, de tejidos resplandores vistan galas las estrellas de rayos el sol mejore (I, vv. 15-20)

toda armonía la luz, 
todo voces el ardor.

[...]

Pues hoy es el más propio día del sol!

[...]

farol

diürno

[...]

ardiente esplendor (III, vv. 3-24)

Al luminoso natal

del sol, hispano monarca,

que sin quemar ilumina

y sin ofender abrasa;

[...]

Pues el sueño de las fuentes

con su hermosa luz despierta, (IV, vv. 1-24)

a los años alegres y festivos

del soberano, el invencible Carlos,

concurren las estrellas con sus luces,

concurren los planetas con sus rayos,

mostrando, en el concilio de luceros

que hubieron menester para formarlo,

el estudio de todas las estrellas,

de todo el cielo el especial cuidado. ( $V$, vv. 1-10)

Asociar el Rey con el sol no es una novedad y la jerónima registra el esquema de intensidad de luz desde el primer momento. Como apuntala García Valdés, «singulariza las loas de Sor Juana el predominio de lo luminoso [...] [y] la obsesión por los efectos de luz, por la luminosidad» ${ }^{4}$. En las loas para el natalicio del Rey, es obvio que los astros y el sol tengan un papel aun más importante por lo que representaban en el diseño cósmico estético sorjuanino: «los hermetistas del Renacimiento y el Barroco no consideraban a los astros como causales de la conducta humana y el curso de la historia, sino como mediaciones simbólicas en la organización dinámica del universo» ${ }^{15}$. Por lo tanto, la luz, las estrellas y el sol aparecen en el comienzo del primer acto de las loas.

Los personajes, acompañados por Coros y Música, presentan a sí mismos como parte central de la acción panegírica que sigue. De hecho:

[t]odas las loas se inician con música y canto en los que los coros - dos, tres y hasta cuatro- adelantan al auditorio el motivo del festejo [...] [l]a clave de la teoría musical de Sor Juana, como la de Calderón, deriva de la teoría pitagórica de los números, de la creencia de que el alma es armónica. El mundo, sólo en la medida en que es un eco de la armonía divina, puede ser eco de la verdadera música [...] 
A esta apoteosis sonora se unen los efectos luminosos en una escena, que bien podría servir de prototipo de teatralidad barroca ${ }^{16}$.

En la primera loa, los cuatro elementos querellosos salen: Fuego, Aire, Agua y Tierra, y se quejan por la armonía que intenta imponer Amor:

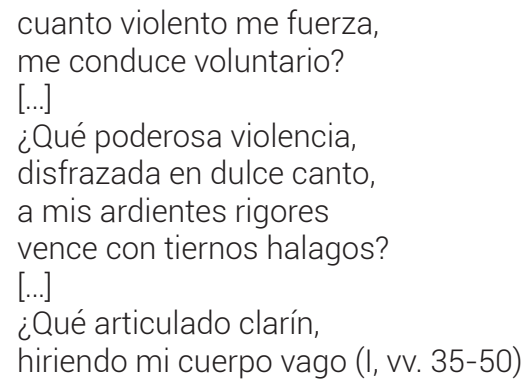

La segunda loa es filosófica y se compone de un soliloquio por parte de Vida de casi 50 versos en el cual insiste en que atribuyan toda la gloria del natalicio del soberano a sus poderes. Arguye que:

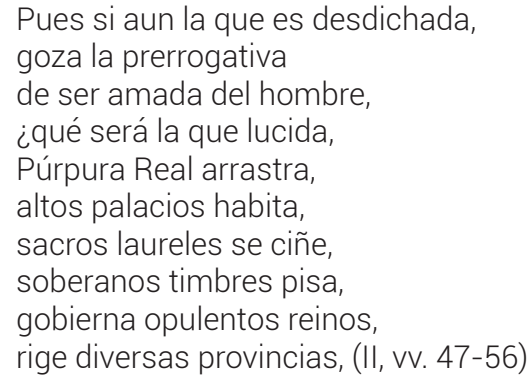

Por la gran estima en que todos tienen la vida, tantos pobres como la realeza, concluye que «el día que al mundo nace / es solamente mi día» (II, vv. 65-66).

En la tercera loa, compuesta cuando el monarca cumplió 20 o 21 años, hay un debate entre Cielo, Sol y Tiempo que dará lugar al siguiente argumento filosófico. Carlos cumple años el 6 de noviembre y Tiempo quiere saber «¿Por qué aqueste día / lo publicáis mayor, sin ser el más largo?» (III, vv. 118-119). Música intenta resolver las dudas de Tiempo: «el día dichoso / que Carlos nace, / no ha menester ser largo / para ser grande.» (III, vv. 131-134). Además, en esta sección, la monja hace alusiones como suele hacer a circunstancias contemporáneas personales o quejas y molestias que los amigos espectadores como Fray Payo o los marqueses de la Laguna habrían entendido. Cuando Tiempo pide una explicación sobre la paradoja del largo del día contrastado con la grandeza del día, la narradora/autora histórica remarca: 
Si acaso mi descuido

os ofendió, pensando

que lo que en mí ignorancia,

en vosotros pudiera ser engaño

(por parecerme a algunos

que, neciamente vanos,

todo lo que no alcanzan

a comprender, condenen por errado). (III, vv. 103-110)

Tanto en sus cartas personales como en algunas obras poéticas hace la misma queja. Además, esta loa que se data de 1681 o 1682 reflejaría, tal vez, el enojo y la desesperación que la monja expresa en su Autodefensa espiritual redactada en los mismos años y que exterioriza la misma queja ${ }^{17}$.

La loa maestra en este grupo es la cuarta porque es un ensayo fortuito para el auto sacramental, El divino Narciso. Como escritora, sor Juana estaba en su mejor momento: fue instigada y aplaudida por producir primores literarios para los nuevos virreyes, los marqueses de la Laguna. Además, en el momento de la composición de esta obra, sus mecenas estaban de plácemes porque había nacido cuatro meses antes su primogénito al cual atribuye la monja la comisión del escrito. En lo que Olivares llama «el vértigo de sinestesias» ${ }^{18}$, la cuarta loa se marca por largos coloquios entre Eolo en el cual predomina lo transparente y efímero, Siringa donde el sonido dibuja el escenario, Flor que pinta con olores y Pan que unifica los sentidos. Eolo, dios del viento, congrega a las aves porque él es:

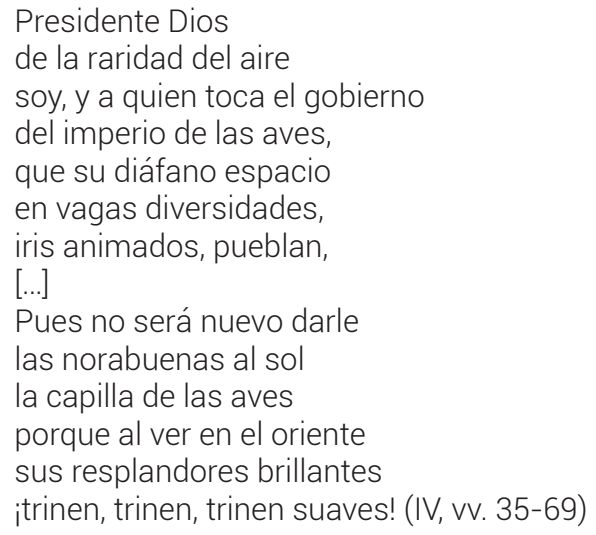

Siringa, diosa de las fuentes, sale y quiere complementar los honores que rinde Eolo: «quien sólo servirle intenta, / quiere acumularle aplausos, / no disputar precedencias» (IV, vv. 86-88). Por medio de sus líneas, compone un lienzo auditivo:

Yo convocaré [...]

todas las fuentes parleras, 
porque unas con transparentes,

y otras con arpadas lenguas,

ya en gorjeos, ya en murmullos,

ya en corrientes, ya en cadencias,

la bienvenida le demos;

y las fuentes lisonjeras

hagan a su luz hermosa

salva con balas de perlas. (IV, VV. 101-110)

En el primer acto donde se crea el nudo del argumento por medio del debate, Flora quiere enseñar que su mundo beneficia más del sol que los otros y alega que:

\author{
Apenas del luciente \\ sienten la hermosa llegada \\ de que la aurora les da \\ rozagantes embajadas, \\ cuando rompiendo el capullo \\ y desabrochando el ámbar, \\ explican la vana pompa \\ de colores y fragancias, \\ y exhalándose en aromas \\ toda su pura substancia, \\ como en retorno del bien \\ a su deidad se consagran, \\ ofreciendo humos sabeos \\ con incensarios de nácar. (IV, VV. 149-162)
}

Pan responde a Eolo, Siringa y Flora sobre los beneficios que recibe del sol (símbolo de Carlos II) y se proclama: «frondoso presidente [...] pues soy Pan, que decir quiere / todo, porque soy el todo / de las deidades agrestes,» (IV, vV. 202-206). La loa repite los esbozos de los ovillejos ecoicos que vendrán en el segundo acto.

Los personajes en la quinta loa son los siete planetas de la lista antigua de Ptolomeo y salen ataviados como los imaginaban los antiguos. «Saturno, viejo; Júpiter, Rey coronado; Marte, armado; Mercurio, con alas y el caduceo; Venus, Dama, con su manzana» ( $V$, entre vv. 24-25). Sol ordena a todos a bajarse y Música hace comparaciones entre Carlos y Adonis por su hermosura y Mercurio por su elocuencia.

Sor Juana alza la loa panegírica a un nuevo nivel y esto se establece en los debates que tejen el quaestio del nudo. Si las loas se han comenzado con las imágenes festivas para fijar el tono, la monja sale con la suya en esta escena versificando debates filosóficos que tanto le gustaban. Los debates consisten en una contienda entre los personajes alegóricos para determinar quién sea el más indicado para alabar al soberano. 


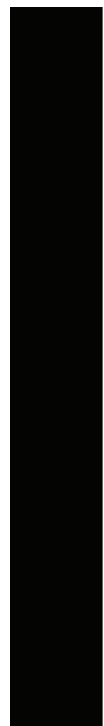

Acto I: (escenas 1,2,[3,4])

Función $\rightarrow$ Debate $\rightarrow$ Nudo

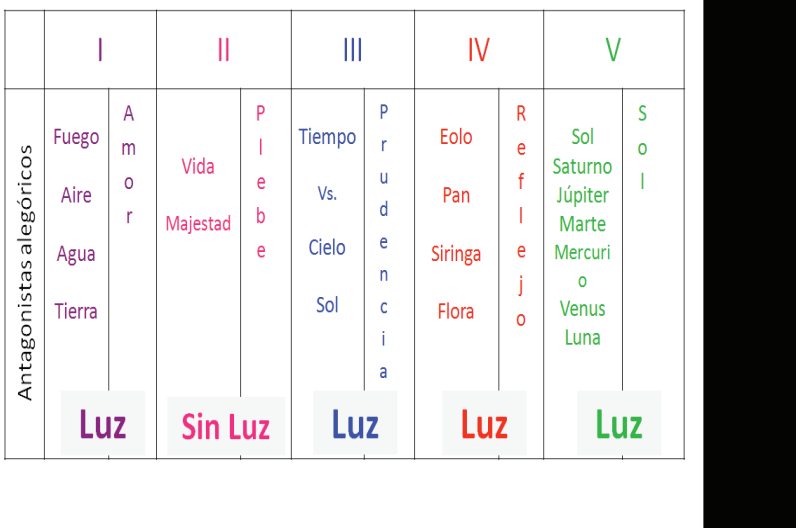

En la primera loa, Amor hace una «fecunda discordia» entre los cuatro elementos. Y declara que «hoy es el día / en que el León de España, Carlos, / para iluminar el mundo / nació entre divinos rayos» (I, vv. 100-103). Pero es en la segunda loa que desarrolla una exposición filosófica magistral. Utilizando 161 versos, Majestad y Vida debaten sobre cuál de los dos es más importante en este natalicio de Carlos II. Mientras en la escena anterior, Vida ha alegado que hasta el ser humano más desdichado codicia la vida más que cualquier otra cosa. Majestad revira aquí:

¿Guarda secretos la noche,

parla noticia el día,

registra espacios el aire,

oculta la tierra minas,

que no penetre, no sepa

esta insaciable fatiga

del hambre sacra del oro,

de la sed de mandar rica? (II, vv. 123-130)

Vida replica con una argumentación filosófica contrastando los derechos naturales y las leyes positivas: «El vivir es en el hombre / lo primero» (II, vv. 155-156) porque como reitera Música «iPues en el ser del hombre / si bien se prueba, / mandar es accidente; / vivir esencia!» (II, vv. 163-166). Majestad arguye que «La materia se anticipa / a la forma; y no, por eso / es por más noble tenida. [...] el hombre, también sin vida / es hombre» (II, vv. 176-193). Pero Vida insiste que el hombre, como concepto, «es alma y que es cuerpo» (II, v. 199) y el «compuesto» de estos dos, es Vida. Sin rendirse, Majestad quiere menospreciar a Vida diciendo que la Vida no es la esencia del hombre porque es finita, a la cual responde:

El ser o no ser mortal

no inmuta la esencia mía, 


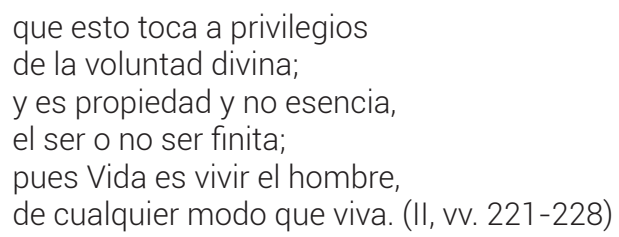

De las cinco loas, ésta es la más filosófica y corresponde a la era en que compuso la Autodefensa espiritual en que sugiere a su confesor que renuncie si no está de acuerdo con sus actividades intelectuales.

En la loa III, Sol y Cielo siguen intentando convencer a Tiempo que un día que es corto de tiempo, por ser noviembre, no es corto, pero, por fin, cede, diciendo: «pues aún repugna / [...] el oír / que se puede dar en una / cantidad el crecimiento / sin aumento» (III, vv. 146-150). Pero, según Música, es fácil porque «retiene las luces que otro Sol le da» (III, v. 160). Tiempo está arrepentido de su error de comprensión y Cielo, Sol y Tiempo se acuerdan de llamar a los súbditos para glorificar al Rey.

La cuarta y más lograda loa poéticamente, procede con las trazas preliminares de los ovillejos ecoicos ${ }^{19}$ que llegarán a su auge en el siguiente acto. En la loa $V$ a los años del Rey, sor Juana explaya conceptos que conocía bien y que incluía en varias obras suyas: la contraposición del efecto de los astros con el concepto cristiano del libre albedrío. La loa cinco, escrita cuando el «Monarca Sol Hispano/ [...] / veintitrés cabales años / cumple de su edad dichosa.» (V, vv. 166-171) es un soliloquio de Sol de casi 100 versos que discute el papel de los astros en un mundo que creía firmemente en el libre albedrío. Pues se adhiere a los conceptos de Ptolomeo, no nada más de la conformación del universo, pero también sobre la mezcla de los efectos astrales combinados con el libre albedrío del hombre. Como dictó Ptolomeo: «"el hombre sabio señorea las estrellas"» ${ }^{20}$. Sin negar el libre albedrío, el texto afirma:

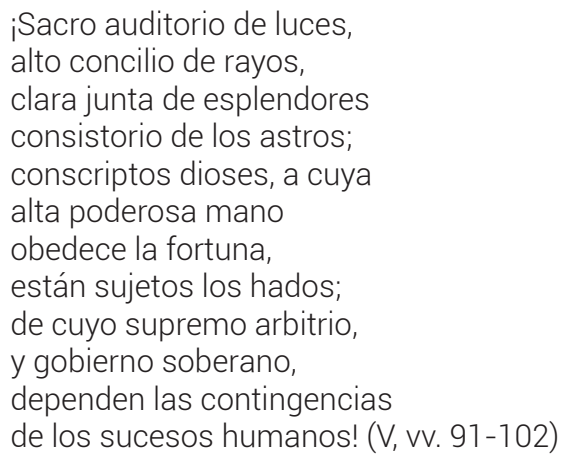

19. En su texto «Perduración del "ovillejo cervantino"», Antonio Alatorre reconstruye la proliferación del ovillejo reconociendo las contribuciones de Salazar y Torres a la usanza de Sor Juana de esta forma poética (1990, pp. 643-674).

20. Méndez Plancarte, 1995, p. 682. 
Por su gran afición por la astrología, de las cinco loas para los años del rey, tres contienen componentes astrológicos.

ACTO II

El Acto I ha trazado «un planteamiento aparentemente irresoluble» ${ }^{21}$, pero dentro del Acto II «aparece [un] juez mediador en la disputa y plantea la divisa sobre la que se organizará el posterior debate y desfile de coadyuvantes» ${ }^{22}$. El Acto II es el desenlace, el momento en que los personajes llegan a un consenso «para así certificar su absoluta sumisión al poder del monarca» ${ }^{23}$.

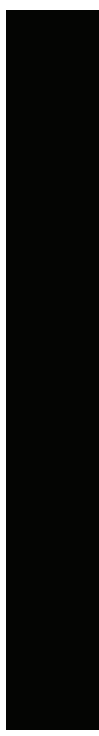

Acto II: $(4,5,6) \quad$ Función $\rightarrow$ Reconciliación $\rightarrow$ Desennlace:

\begin{tabular}{|c|c|}
\hline Juez Mediador & Atributos Alegóricos \\
\hline Amor & 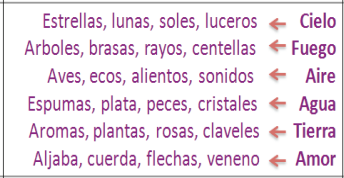 \\
\hline Plebe & 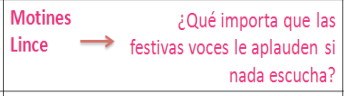 \\
\hline Prudencia & $\begin{array}{r}\text { iQue el que del común orden/ se mira } \\
\text { exento,/ no ha menester los años/ para ser } \\
\text { cuerdo! }\end{array}$ \\
\hline Reflejo & $\begin{array}{l}\text { Y pues Josef solo/ ser retrato puede, / que } \\
\text { sus perfecciones/ copie dignamente }\end{array}$ \\
\hline Sol & \begin{tabular}{r|} 
Autoridad \\
Poder \\
Valor
\end{tabular} \\
\hline
\end{tabular}

En la primera loa, sor Juana incluye elementos para elogiar y para pedir clemencia al poder. Con el auxilio de Música, los cuatro elementos son convocados, armónicamente, gracias a Amor, para rendir sus tributos a las gestas militares españolas. Amor intenta conciliar estas potestades, pidiéndoles generosidad. Fuego da el tributo de centellas y predomina el augurio de exitosas «actividades de fuego / de militares ardores» (I, vv. 170-171). Agua rinde sus honores mencionando las proezas del imperio: «en dos mundo espante / ver que no cabéis en uno;» (I, vV. 200-201). Tierra ha sido regada y fecundada por la sangre de los adversarios y jura lealtad: «La tierra rendida os ame, / y su imperio os atribuya, / no llamando parte suya / la que vuestra no se llame» (I, vv. 210-213). Amor proclama que «el yugo de la obediencia / [es] culto de deidad» (I, vv. 232-233).

En la segunda loa, el desenlace es más paulatino subrayando la cualidad filosófica de los versos. Salen Naturaleza y Lealtad y regañan a Vida y Majestad por 
sus andanzas verbales filosóficas. En la loa tercera, Sol, Cielo y Tiempo hacen un juego con la numerología cuando denominan al monarca: «Carlos Segundo / [...] / Carlos Primero / [...] / El sexto Carlos» (III, vv. 220-222). Es Primero porque como alegó Calderón en La nave del mercader, «aun naciendo Segundo, / naciste a ser Primero!» ${ }^{24}$. Es el «sexto Carlos» porque según la numerología simbólica, «"el seis es el primer número perfecto"» ${ }^{25}$.

Compuesta de casi 80 versos, «[t]oda esta Escena IV es una nueva recapitulación y amplificación de estribillos, inagotable en sus invenciones estróficas (variaciones del juego de "Ovillejos ecoicos")» ${ }^{26}$. Eolo, Siringa, Flora y Pan elogian el soberano con una imaginería en la cual prima la sinestesia. En la quinta loa, también trata de los obsequios del universo a Carlos II. De nuevo, los planetas están reunidos y cada uno confiere atributos que corresponden a su reino: Saturno-Autoridad, JúpiterPoder, Sol-Entendimiento, Marte-Valor, Mercurio-Elocuencia, Venus-Hermosura, Luna-Entendimiento.

El desenlace se caracteriza por los esquemas métricos y por una imaginería más desarrollada. La primera loa es singular por el coro de los elementos que recrean los ovillejos ecoicos reales inspirados en Salazar y Torres. Como declara Alatorre: «El Cielo, el Fuego, el Aire, la Tierra y el Amor declaran cada uno en un ovillejo los dones que ofrecen al adorado Carlos II y los versos cortos y las recolecciones corren al cargo de la Música» ${ }^{27}$. Por ejemplo, según Música, Cielo aporta «Estrellas, Luna, Soles y Luceros» (I, v. 249); Fuego: «Ardores, Brasas, Rayos y Centellas» (I, v. 261); Aire: «Aves, Ecos, Alientos y Sonidos» (I, v. 273); Agua: «Espumas, Plata, Peces y Cristales» (I, v. 285); Tierra: «Aromas, Plantas, Rosas, y Claveles» (I, v. 297); Amor: «Aljaba, Cuerda, Flechas y Veneno» (I, v. 309).

La segunda loa manda un mensaje político por parte de Plebe que sale de Villana e inmediatamente empieza a reprender a Majestad y Vida por su debate filosófico:

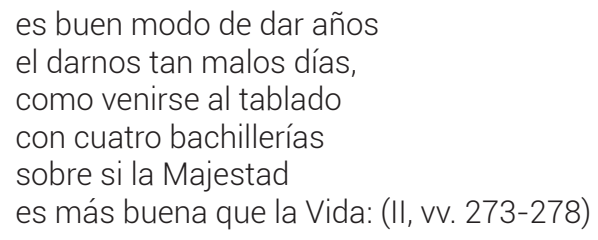

En una especie de amenaza, Plebe demuestra su actitud indiferente ante la nobleza y chantajea con: «en empezando mi grita, / par Dios, quieran o no quieran, / que han de hacer lo que yo diga!» (II, vv. 292-294). Lealtad anima a Plebe a ser fiel y haciendo mención de un motín que seguramente era un peligro en cualquier momento en la Nueva España, por ejemplo, de 1680 hasta 1692, una insurrección 
indígena que «desafió el control español de Nuevo México» ${ }^{28}$ no pudo ser controlado hasta las negociaciones del conde de Galve tuvieron éxito. Plebe revira:

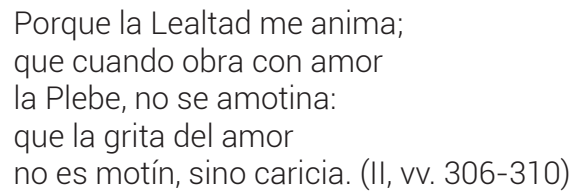

Vida hace eco de los sentimientos lopescos del vulgo: «Bien dice la Plebe; y es / bien que su gusto se siga: / que tal vez los ignorantes / a los discretos avisan» (II, vv. 311-314). Sorprendentemente, no es Plebe que recita los siguientes versos, sino Naturaleza: «Y yo soy de la misma; / pero estando ausente Carlos, / ¿qué importa que las festivas / voces le aplaudan, si nada / escucha?» (II, vv. 316-320). Lealtad justifica la celebración por el ausente monarca atribuyéndole poderes especiales: «que mañosamente fina, / siendo lince de distancias, / aun halla en la ausencia vista» (II, vv. 324-326). Mientras Plebe demanda sus derechos y declara su lealtad, Naturaleza cuestiona la práctica de hacer festividades para el natalicio de un monarca ausente. Lealtad le atribuye a Carlos II los poderes de un lince para satisfacer a Naturaleza que, desde el punto de vista del sentido común, no comprende la práctica de hacer fiestas para una persona ausente.

El desenlace de la loa tercera consiste en resolver un debate entre Juventud y Tiempo. La duda que expone Juventud es la factibilidad de celebrar los años de una persona tan joven ya que cumplía 20 o 21 años. Pero Tiempo justifica todo en unísono con Música: «iPorque de un Rey supremo / la vida heroica / la componen los triunfos / y no las horas!» (III, vv. 268-271). La cuarta loa enfatiza dos conceptos: primero, la ausencia de Carlos II físicamente en el Nuevo Mundo.

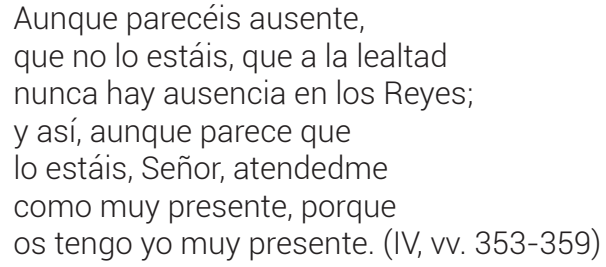

Segundo, exalta al recién nacido hijo de los Virreyes, don José de la Cerda. Como hemos comentado, los virreyes tenían una predominancia sobre el soberano español en cuanto a honores en estas festividades porque ejercían más poder inmediato sobre los súbditos. Por esto, según Siringa, el bebé es el único que puede ser un reflejo de Carlos II. Y como presagio del imaginario del juego de reflejos que la escritora utiliza en El divino Narciso, Siringa ordena: «si retratar pretendes / las perfecciones de Carlos, / nadie parecerse puede / sino el Reflejo, a sus luces» (IV, vv. 375-378). El Reflejo, don José de la Cerda es «perfecta imagen / suya» (IV, vV. 389-390).

28. Jáuregui, 2008, p. 209, ver nota. 


\section{ACTO III}

El tercer acto es la conclusión de las loas e incluye toda la retórica de rigor que acompaña a esta función.

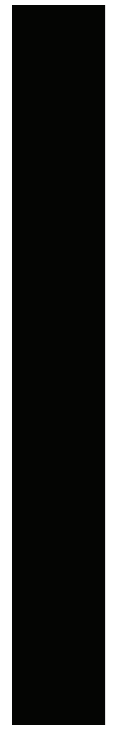

Acto III: $(6,7)$ Función $\rightarrow$ Salutación

\begin{tabular}{|c|c|c|}
\hline 1 & $\|$ & III \\
\hline \multirow[b]{2}{*}{$\begin{array}{c}\text { Apostrofe al } \\
\text { Arzobispo-Virrey } \\
\text { (Callado y Pastor) }\end{array}$} & \multirow[b]{2}{*}{$\begin{array}{l}\text { Intertextualidad: Mención } \\
\text { de la obra de Calderón que } \\
\text { sigue: } \\
\text { En esta vida todo es } \\
\text { verdad y todo es mentira } \\
\text { (1659) }\end{array}$} & Prudencia: \\
\hline & & $\begin{array}{l}\text { "Para que gocen/ los reyes } \\
\text { la suficiencia/ digna del } \\
\text { Real decoro,/ Dios le } \\
\text { dispensa/ todas las leyes } \\
\text { comunes." }\end{array}$ \\
\hline \multirow{2}{*}{$\begin{array}{l}\text { Apostrofe al Rey } \\
\text { (Ninguna mención del } \\
\text { senado, tribunal, etc.) }\end{array}$} & \multirow{2}{*}{$\begin{array}{l}\text { Meta teatro: Plebe: "Yoo os } \\
\text { lo diré; que cansados/de ver } \\
\text { la loa tan prolija/empiezan } \\
\text { yala comedia" } \\
\text {-Plebe asigna papeles: } \\
\text { - Majestad: Cintia } \\
\text { - Lealtad: Libia } \\
\text { - Naturaleza: Ismenia }\end{array}$} & $\begin{array}{l}\text { "Siendo estudio de las } \\
\text { luces,/ siel Sol de sus } \\
\text { rayos vive/ por ceremonia } \\
\text { del tiempo/ sin ser suyos } \\
\text { se permiten" }\end{array}$ \\
\hline & & \begin{tabular}{|l} 
María Luisa de Orleáns \\
cerda \\
Divina Consorte \\
Senado \\
Ciuddd \\
Las Damas
\end{tabular} \\
\hline
\end{tabular}
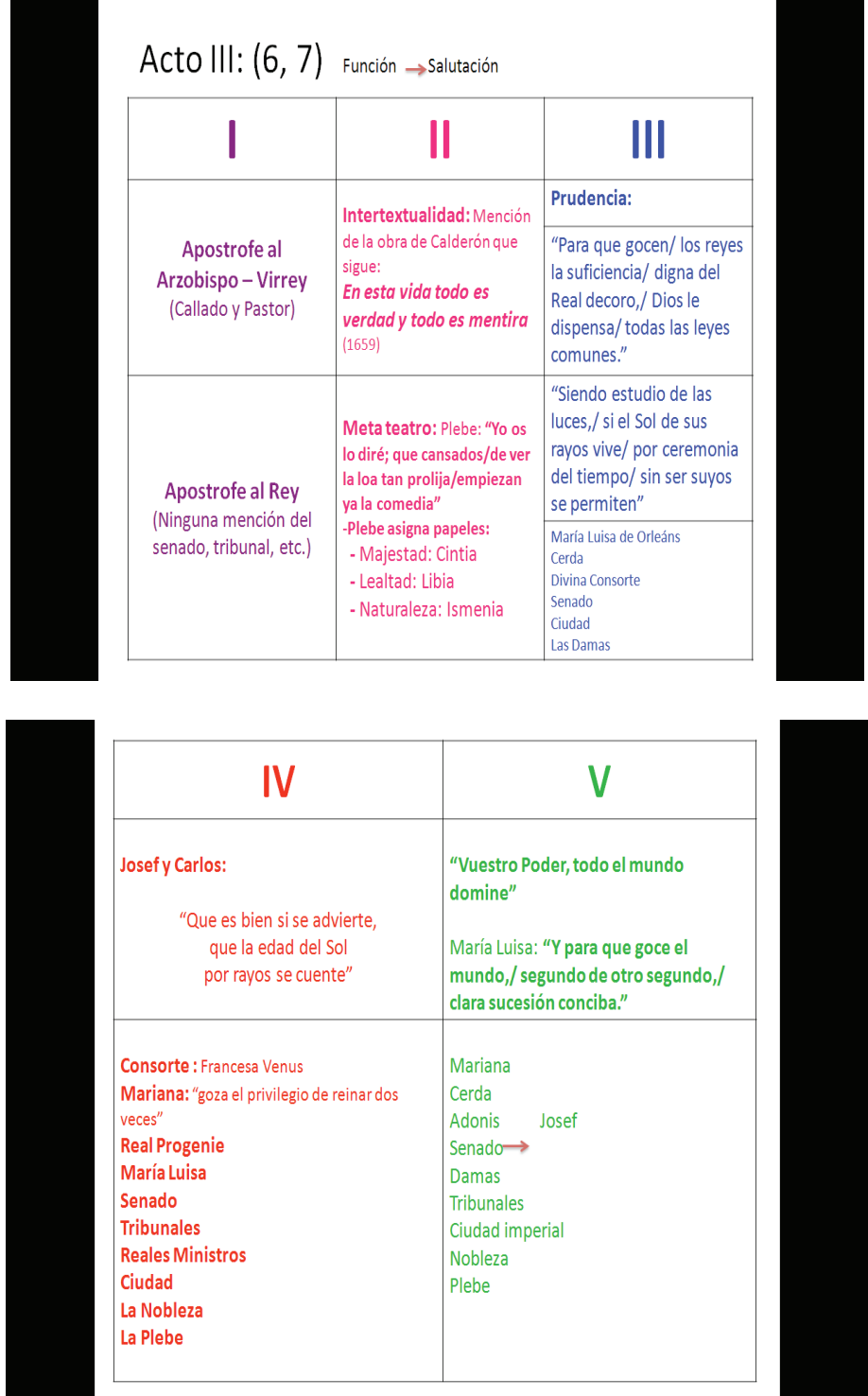

\begin{tabular}{|c|c|}
\hline IV & $\mathbf{V}$ \\
\hline $\begin{array}{l}\text { Josefy Carlos: } \\
\text { "Que es bien si se advierte, } \\
\text { que la edad del Sol } \\
\text { por rayos se cuente" }\end{array}$ & $\begin{array}{l}\text { "Vuestro Poder, todo el mundo } \\
\text { domine" } \\
\text { María Luisa: "Y para que goce el } \\
\text { mundo,/ segundo de otro segundo,/ } \\
\text { clara sucesión conciba." }\end{array}$ \\
\hline $\begin{array}{l}\text { Consorte : Francesa Venus } \\
\text { Mariana: "goza el privilegio de reinar dos } \\
\text { veces" } \\
\text { Real Progenie } \\
\text { María Luisa } \\
\text { Senado } \\
\text { Tribunales } \\
\text { Reales Ministros } \\
\text { Ciudad } \\
\text { La Nobleza } \\
\text { La Plebe }\end{array}$ & $\begin{array}{l}\text { Mariana } \\
\text { Cerda } \\
\text { Adonis Josef } \\
\text { Senado } \longrightarrow \\
\text { Damas } \\
\text { Tribunales } \\
\text { Ciudad imperial } \\
\text { Nobleza } \\
\text { Plebe }\end{array}$ \\
\hline
\end{tabular}

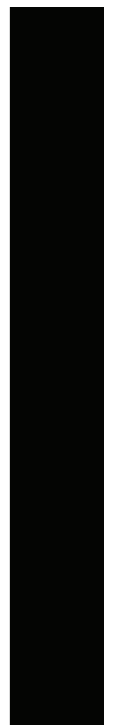

En la primera loa, la sección está dedicada al Arzobispo-Virrey Fray Payo Enríquez de Ribera, amigo y protector de la monja. La escena última con los deseos de un largo reino: «aunque el Mar / surquen más alados leños, / nunca nos traigan más nueva, / que de gozaros de nuevo.» (I, vv. 362-365) Payo duró por lo menos tres años más en el puesto. 
Además de reiterar la lealtad a Carlos de Plebe: «iCarlos de mi corazón, / en quien hay tanta excelencia, / que a no haceros Rey la herencia, / os hiciera la elección:» (II, vv. 405-408), cumple con las otras salutaciones, como a la Reina María Luisa de Orleáns con la cual se casó Carlos II en 1679, y los marqueses de la Laguna que tomaron posesión en 1680 y al Senado que califica como: «en paz y justicia, / de Minos afrenta, / de Licurgo envidia» (II, vv. 454-456). La loa tercera reitera que pese los 20 o 21 años que cumplía el monarca, es muy sabio como dicta Prudencia: «iQue el que del común orden / se mira exento, / no ha menester los años / para ser cuerdo!» (III, vv. 296-299).

La cuarta loa tiene fines de rendir pleitesía localmente a los virreyes. En contraste con esta escena en las otras loas, estos versos contienen varios argumentos. El primogénito, recién nacido José, es representado por Reflejo. Dado que «la edad del Sol / por rayos se cuente» (IV, vv. 418-419) y no por años, es apto, por su alcurnia, de ser el Reflejo del Rey. Reflejo refiere al «Sol Carlos» que tiene cifrado la palabra «Sol Claro» explicando el anagrama imperfecto como:

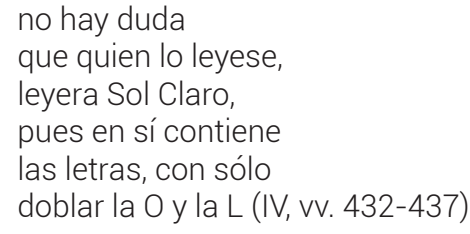

Emparentados por su descendencia de Alfonso el Sabio, el texto quiere enseñar relaciones estrechas que realmente no existieron:

cual Reflejo,

en ella aparece

José, del Sol Carlos

claro descendiente:

José que, del Sol

imagen, contiene

de Sangre, que es luz,

puros rosicleres; (IV, VV. 462-469)

Reflejo hace patente que apetece más ser un leal vasallo que un real pariente y remata con:

Aunque impedida

su lengua enmudece,

da, en sus venas, voces

la sangre que hierve:

que, como es de Carlos,

desde ahora quiere

salir de sus venas

para defenderle (IV, vv. 500-507) 
Cumple con su encargo de celebrar el natalicio del rey mientras glorifica al primogénito de sus amigos y más cercanos aliados, los virreyes. La quinta loa como la cuarta, no ha avanzado aún a las salutaciones al público, sino representa a los planetas rindiendo honores al Rey y cediendo sus poderes en un acto de humildad.

Las conclusiones contienen unas variaciones, pero, en general, siguen la fórmula de los finales dramáticos panegíricos. La conclusión de la primera loa es la más breve y simple. La acotación dice: «Apóstrofe al Rey» y hace uso de la falsa modestia para disculparse por la loa. En la segunda loa funciona como conclusión pero, también, como introducción a la comedia calderoniana que sigue, En esta vida, todo es verdad y todo es mentira. Desde dentro, vociferan: «iViva Focas! / [...] / ¡Viva Cintia!» (II, Vv. 479-480) en referencia a dos de los personajes de la obra. Utilizando una técnica teatral innovadora, Plebe se queja de la loa y quiere que comience la comedia. Lealtad resalta que faltan actores, pero Plebe tiene una solución metateatral:

Y con que tú hagas a Cintia

Majestad; y la Lealtad,

a la persona de Libia;

Naturaleza, el papel

que es de Ismenia (II, vv. 500-504)

Sin saludar aún a los otros dignatarios civiles, exclaman: «iViva Focas, viva Cintia / [...] / Vivan Carlos y María!» (II, vv. 512-514). Además de cumplir con la reconciliación formularia de los personajes alegóricos, distendidamente, la tercera loa aclama tanto a los destinatarios virtuales, María Luisa de Orleáns y hace alarde de Carlos II atribuyéndole, otra vez, poderes de lince, como en la loa segunda. Como debería ser por la importancia para su bienestar inmediato, exalta a los virreyes, los marqueses de la Laguna, y, después, aplaude al Senado, la Ciudad, y las Damas. En una referencia metateatral, tanto Sol como Cielo hablan de sí mismos como actores en esta obra: «yo el papel del Sol hice / [...] y, que el papel del Cielo / hice» (III, vV. 405 y 416-417).

La loa cuarta, auspiciada por el recién nacido, José, hijo de los marqueses de la Laguna, también termina con las aclamaciones de rigor a los poderes ausentes y presentes:

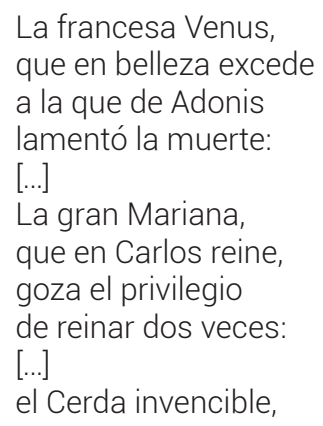


[...]

la alta María,

tan divina siempre,

[...]

el José glorioso

$[\ldots]$

el docto Senado

[...]

Y los Tribunales,

a quien ennoblecen

de Reales Ministros

cargos preminentes;

y las bellas Damas,

[...]

y la gran Ciudad,

la Nobleza y Plebe,

leal cuerpo de tantos

timbres diferentes, (IV, vv. 559-609).

Con la valiosa amistad de los virreyes bien afianzada, además, que fue un encargo por parte de ellos a beneficio de su hijo primogénito recién nacido, la loa finaliza con una doble aclamación, a Carlos, pero, también, al niño José:

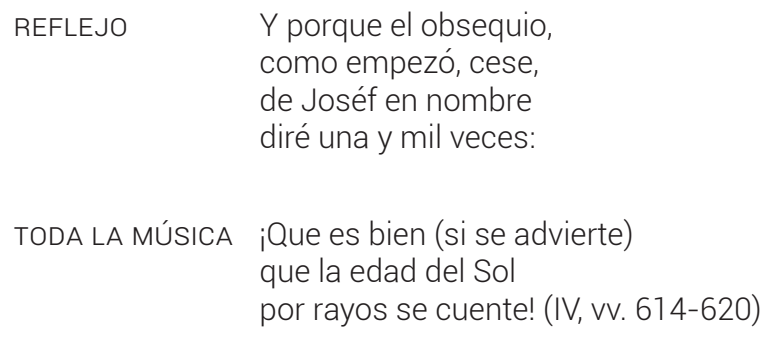

Además de los homenajes reglamentarios en la loa quinta, también hay mención de los deseos universales que María Luisa de Orleáns conciba un sucesor al trono: «Y para que goce el Mundo, / segundo, de otro Segundo, / clara Sucesión conciba» ( $V$, vv. 365-367). Las demás autoridades son mencionadas y sor Juana no se olvida de incluir en sus honores a la Ciudad y a la Plebe.

\section{CONCLUSIONES}

Muchas veces, forma es fondo, por esto, dividiendo las loas a los años del Rey, en actos ayuda la comprensión de la morfología funcional de estas obras sorjuaninas. Los textos siguen una 'plantilla', ciertos paradigmas estructurales que asumen un papel funcional: crear un nudo por medio de la discordia, un desenlace aportado por un juez conciliador y la conclusión sistematizada que remarca el elogio del monarca mientras saluda a los asistentes ilustres. Pero, la monja agrega intereses siempre personales y locales a sus textos. Llenos de luz, sinestesia, ovillejos ecoi- 
cos, fórmulas curativas astrológicas y emblemas, la monja levanta la loa palaciega a nuevos niveles estéticos convirtiéndolas en comedias en miniatura.

\section{BIBLIOGRAFÍA}

Alatorre, Antonio, «Perduración del "ovillejo cervantino"», Nueva Revista de Filología Hispánica, XXXVIII, 1990, pp. 643-674.

Arellano, Ignacio, Estructuras dramáticas y alegóricas en los autos de Calderón, Pamplona/Kassel, Universidad de Navarra/Edition Reichenberger, 2001.

Curcio-Nagy, Linda A., The Great Festivals of Colonial Mexico City, Performing Power and Identity, Albuquerque, University of New Mexico, 2004.

Farré, Judith, «A propósito de las metáforas y los tópicos panegíricos», AISO, Actas VI, Centro Virtual Cervantes, 2002, pp. 775-785.

García Valdés, Celsa, «Una síntesis de las artes en el Barroco hispánico: las loas cortesanas de sor Juana», Temas del Barroco hispánico, ed. Ignacio Arellano y Eduardo Godoy, Madrid/Frankfurt am Main, Iberoamericana/Vervuert, 2004, pp. 107-127.

Jáuregui, Carlos A., Canibalia. Canibalismo, calibanismo, antropofagia cultural y consumo en América Latina, Madrid/Frankfurt am Main, Iberoamericana/Vervuert, 2008.

Méndez Plancarte, Alfonso, «Notas», Obras completas de Sor Juana Inés de la Cruz, III, México, Fondo de Cultura Económica, 1995, pp. 652-691.

Olivares, Rocío, «Las loas herméticas de sor Juana», Etiópicas, 4, 2008, pp. 166187.

Rivera, Octavio, «Teatro y poder en el virreinato de Nueva España: las loas profanas de sor Juana Inés de la Cruz», ALEUA/13, 1999, pp. 127-141.

Sor Juana Inés de la Cruz, «Loa en celebración de los años del rey nuestro señor Don Carlos II», Obras completas de Sor Juana Inés de la Cruz, III, ed. Alfonso Méndez Plancarte, México, Fondo de Cultura Económica, 1995, pp. 279-376.

Tapia, Aureliano, «Estudios y notas», Carta de sor Juana Inés de la Cruz a su confesor. Autodefensa espiritual, Monterrey, Producciones al voleo el troquel, 1993, pp. 59-64. 